\title{
Multiple Interacting Sites of Ectopic Spike Electrogenesis in Primary Sensory Neurons
}

\author{
Ron Amir, ${ }^{1}$ Jeffery D. Kocsis, ${ }^{2}$ and Marshall Devor ${ }^{1}$ \\ ${ }^{1}$ Department of Cell and Animal Biology and the Center for Research on Pain, Institute of Life Sciences, Hebrew University of Jerusalem, Jerusalem 91904, \\ Israel, and ${ }^{2}$ Department of Neurology, Paralyzed Veterans of America/Eastern Paralyzed Veterans of America Neuroscience and Regeneration Research \\ Center, Yale University School of Medicine, New Haven, Connecticut 06516
}

Ectopic discharge generated in injured afferent axons and cell somata in vivo contributes significantly to chronic neuropathic dysesthesia and pain after nerve trauma. Progress has been made toward understanding the processes responsible for this discharge using a preparation consisting of whole excised dorsal root ganglia (DRGs) with the cut nerve attached. In the in vitro preparation, however, spike activity originates in the DRG cell soma but rarely in the axon. We have now overcome this impediment to understanding the overall electrogenic processes in soma and axon, including the resulting discharge patterns, by modifying the bath medium in which recordings are made. At both sites, bursts can be triggered by subthreshold oscillations, a phasic stimulus, or spikes arising elsewhere in the neuron. In the soma, once triggered, bursts are maintained by depolarizing afterpotentials, whereas in the axon, an additional process also plays a role, delayed depolarizing potentials. This alternative process appears to be involved in "clock-like" bursting, a discharge pattern much more common in axons than somata. Ectopic spikes arise alternatively in the soma, the injured axon end (neuroma), and the region of the axonal T-junction. Discharge sequences, and even individual multiplet bursts, may be a mosaic of action potentials that originate at these alternative electrogenic sites within the neuron. Correspondingly, discharge generated at these alternative sites may interact, explaining the sometimes-complex firing patterns observed in vivo.

Key words: 4-AP; afterdischarge; ectopic firing; pain; repetitive firing; subthreshold oscillations

\section{Introduction}

Repetitive discharge that develops ectopically in injured afferents after nerve trauma makes a significant contribution to chronic neuropathic dysesthesia and pain (Sheen and Chung, 1993; Devor and Seltzer, 1999; Sukhotinsky et al., 2004). The discharge is attenuated by blockers of voltage-sensitive $\mathrm{Na}^{+}$channels, including systemic local anesthetics, tricyclics, and certain anticonvulsants, drugs that attenuate pain in patients with neural trauma (Catterall, 1987; Lai et al., 2004). Likewise, it is facilitated by blockers of voltage-sensitive $\mathrm{K}^{+}$channels such as tetraethyl ammonium (TEA) and 4-aminopyridine (4-AP), drugs that exacerbate neuropathic dysesthesias and pain (Devor, 1983; Kocsis et al., 1986; Chabal et al., 1989; Lees, 1996; Amir et al., 2002b). Studies of dorsal root ganglion (DRG) neurons in vitro have begun to uncover the cellular processes underlying this discharge and to account for characteristic discharge patterns.

High-frequency subthreshold membrane potential oscillations are an essential trigger of ectopic discharge. The oscillations overcome membrane accommodation that normally precludes

Received 0ct. 5, 2004; revised Dec. 19, 2004; accepted Jan. 11, 2005.

This work was supported by grants from the United States-Israel Binational Science Foundation, the GermanIsraeli Foundation for Scientific Research, and the Charles Smith Family National Institute for Psychobiology in Israel. We thank Brian Everill for helpful comments.

Correspondence should be addressed to Dr. Ron Amir, Department of Cell and Animal Biology, Institute of Life Sciences, Hebrew University of Jerusalem, Jerusalem 91904, Israel. E-mail: ronamir@pob.huji.ac.il. D01:10.1523/JNEUROSCI.4118-04.2005

Copyright $\odot 2005$ Society for Neuroscience $\quad$ 0270-6474/05/252576-10\$15.00/0 repetitive firing in DRG neurons in response to tonic or slowonset physiological stimuli (Amir et al., 1999; Liu et al., 2000; Xing et al., 2001). Some injured afferents fire singlet spikes at low frequency with an irregular pattern. Each such spike is triggered by the upstroke of an oscillation sinusoid that crosses threshold (Amir et al., 2002a). Other neurons fire sustained trains of regularly spaced spikes, or sequences of spike bursts. Here, only the first impulse in the train is triggered by an oscillation sinusoid; subsequent spikes are triggered by depolarizing afterpotentials (DAPs) (Amir et al., 2002a; Liu et al., 2002). Bursting may occur when tonic firing activates a prolonged afterhyperpolarization (AHP), which stops the firing until the next burst is triggered. Oscillations reflect rapidly reciprocating transmembrane $\mathrm{Na}^{+}$ and $\mathrm{K}^{+}$currents, DAPs reflect rebound from the postspike hyperpolarization, and prolonged AHPs reflect recruitment of a $\mathrm{Ca}^{2+}$-activated $\mathrm{K}^{+}$current (Amir and Devor, 1997; Amir et al., 1999, 2002a; Pedroarena et al., 1999; Wu et al., 2001; Xing et al., 2003). Oscillations and DAPs are related, but not identical, phenomena. Some cells, for example, have DAPs but not oscillations (Amir et al., 2002a)

Despite progress in understanding neuropathic electrogenesis, significant gaps remain. Most important, although both DRG somata and neuroma endings contribute to ectopia in vivo, ectopic discharge originating at the site of axonal injury is rarely encountered under in vitro conditions in which ectopia is recorded in the cell soma. This limits our ability to infer whether the same electrogenic mechanisms apply in the cell soma and axon, 
and it restricts our vision to a single ectopic source, although we know that in vivo, there may be multiple interacting sources. A potential solution to this problem arose during the course of recent studies in which a variety of $\mathrm{K}^{+}$channel blockers were applied (Amir et al., 2002b). All blockers enhanced ectopic firing, but one of them, 4-AP, appeared to facilitate electrogenesis in axons. Using this pharmacological tool, we were able to document ectopic discharge initiation in both the axons and the DRG and, hence, to compare the electrogenic process at these sites and to observe interactions.

\section{Materials and Methods}

Electrophysiological preparation. Recordings were made from DRG neurons in juvenile (18-26 d of age; 43-75 g) and adult (290-310 g) Wistarderived Sabra strain rats (Lutzky et al., 1984). Some animals underwent unilateral neurectomy 4 or $6 \mathrm{~d}$ before electrophysiological evaluation; in others, neurectomy was acute. Briefly, under pentobarbital anesthesia (Nembutal; $50 \mathrm{mg} / \mathrm{kg}$, i.p.), the sciatic nerve was exposed in the popliteal fossa, tightly ligated with 5-0 silk, and cut just distal to the ligature. Approximately $5 \mathrm{~mm}$ of the distal nerve stump was excised. Surgical wounds were closed in layers, and the animals were treated with a topical bacteriostatic powder and 50,000 U/kg penicillin (intramuscular). Recovery was uneventful. All protocols were approved by the Institutional Animal Care and Use Committee of the Hebrew University of Jerusalem and followed the ethical guidelines of the International Association for the Study of Pain.

On the day of the experiment, animals were overdosed with pentobarbital sodium ( $\geq 60 \mathrm{mg} / \mathrm{kg}$, i.p.) and killed by carotid exsanguination. L4 or L5 DRGs were excised with their dorsal roots (DRs), spinal nerve and a variable length of sciatic nerve attached, and immersed in ice-cold Krebs' solution containing the following (in $\mathrm{mm}$ ): $124 \mathrm{NaCl}, 26$ $\mathrm{NaHCO}_{3}, 3 \mathrm{KCl}, 1.3 \mathrm{NaH}_{2} \mathrm{PO}_{4}, 2 \mathrm{MgCl}_{2}$, and 10 dextrose, saturated with $95 \% \mathrm{O}_{2}$ and $5 \% \mathrm{CO}_{2}$, pH $7.4(290-300 \mathrm{mOsm})$. In nerve-injured animals, the neuroma was always included. After $60 \mathrm{~min}$ of recovery, ganglia with DR and cut nerve end were pinned in a single compartment recording chamber and superfused at $1-3 \mathrm{ml} / \mathrm{min}$ with the Krebs' solution, to which $2 \mathrm{~mm} \mathrm{CaCl}_{2}$ was added (room temperature, $\sim 20^{\circ} \mathrm{C}$ ). In juvenile rats, the DRG capsule could be penetrated by recording electrodes, whereas in adults, it was necessary to slit the capsule open to successfully impale DRG neurons. Results from these two groups of animals did not differ in any noticeable way, however, and have been combined.

Sharp glass microelectrodes were used for intracellular recording and stimulation of DRG neurons in current-clamp mode (20-50 M $\Omega$ filled with $3 \mathrm{M} \mathrm{KCl}$ ). In many experiments, 4-AP (Sigma, St. Louis, MO) was added to the superfusion solution at a concentration of $1 \mathrm{~mm}$. This concentration is widely used in vitro, although in slice preparations where capsular diffusion barriers are absent, a lower concentration may be preferred [e.g., $200 \mu \mathrm{M}$ used by Pedroarena et al. (1999)]. All cells reported here had a stable resting membrane potential $\left(V_{\mathrm{r}}\right)$ more negative than $-45 \mathrm{mV}$ and an overshooting spike on intracellular (somatic) or extracellular axonal stimulation. Data were recorded digitally on videotape. The compound action potential, evoked by sciatic/spinal nerve stimulation and monitored on the DR using a suction electrode, was an indicator of spike propagation through the ganglion (Fig. $2 A$ ).

Because the preparation did not permit determination of receptive fields, neurons were categorized by axonal conduction velocity $(\mathrm{CV})$ and the shape of the intracellularly recorded spike as described previously (Koerber and Mendell, 1992; Amir and Devor, 1996). Here, we focus exclusively on myelinated (A-) neurons ( $\mathrm{CV},>1 \mathrm{~m} / \mathrm{s})$. CV is not much reduced by axotomy at the survival times used, and even if it had been, the slowest conducting axons included in our sample would nonetheless have been A-fibers before axotomy. Although in normal tissue nociceptive signaling is attributable primarily to neurons with slowly conducting myelinated $(\mathrm{A} \delta$ ) axons and unmyelinated $(\mathrm{C}-)$ axons, a substantial proportion of A-fiber nociceptors have rapidly conducting $(\mathrm{A} \beta$-) axons (Djouhri and Lawson, 2004). Moreover, neurons with $\mathrm{A} \beta$ axons are the major cell type responsible for tactile hypersensitivity in neuropathic pain (Torebjork et al., 1992; Devor and Seltzer, 1999).
After sciatic nerve cut, many neurons in both the L4 and L5 DRGs remain intact as their axons reach target organs via peripheral nerves that branch off the nerve trunk proximal to the cut (Devor et al., 1985). Cells in chronically neurectomized preparations were identified as intact or axotomized by placing an $\mathrm{Ag} / \mathrm{AgCl}$-stimulating electrode pair across the sciatic nerve $\sim 5 \mathrm{~mm}$ proximal to the neuroma. A spike recorded in the soma in response to sciatic nerve stimulation indicated that the cell had in fact been axotomized.

Electrophysiological analysis. Some DRG neurons show sinusoidal subthreshold oscillations in their membrane potential $\left(V_{\mathrm{m}}\right)$ (Amir et al., 1999, 2002a,b; Xing et al., 2001). To analyze these oscillations, signals were bandpass filtered at $1 \mathrm{~Hz}$ to $10 \mathrm{kHz}$ and digitized at $5 \mathrm{kHz}$. Oscillation frequency was quantified as power spectral density during 1-4 s spike-free epochs and processed using a Fast Fourier Transform (FFT) routine (CP Analysis; DataWave Technologies, Minneapolis, MN). Oscillations were usually obvious but, when necessary, we used as a formal criterion that amplitude peaks be at least $1.5 \times$ the amplitude of the background noise level present during brief pauses in the oscillations and/or that there be a distinct peak in the FFT plot at the frequency expected from visual inspection of the voltage trace. Because the presence and amplitude of the oscillations are voltage sensitive, we usually examined cells at $V_{\mathrm{r}}$ and then depolarized the membrane in a slow ramp and hold ( $\sim 20 \mathrm{mV} / \mathrm{s}$; hold, $>2 \mathrm{~s}$ ) until oscillations occurred or until $V_{\mathrm{m}}$ reached more than $-20 \mathrm{mV}$. In the presence of $4-\mathrm{AP}$, the prevalence of oscillatory behavior and repetitive firing was not significantly different in acute and chronic axotomized cells; therefore, we have combined the results from these groups.

A second type of analysis involved the regularity of the interspike interval (ISI) and the interval between spike bursts. We observed two quite different styles of burst firing: (1) neurons that fired bursts triggered by oscillations and maintained by DAPs (in these cells, the ISI within bursts was regular, but the interval between bursts was variable) and (2) neurons that fired in a "tonic autorhythmic" pattern in the absence of visible oscillations and DAPs [in these cells, singlet spikes, or multiplet bursts (doublets, triplets, etc.), recurred in a highly regular, "clock-like" pattern]. To distinguish these contrasting firing patterns, we used a "variability index." The index was defined as the ratio between the $\mathrm{SD}$ and the mean of the interval between bursts recorded at the same $V_{\mathrm{m}}$. Low values of the variability index indicate highly regular, clock-like burst discharge. High values indicate an irregular pattern of bursting. The interval between bursts or multiplets was measured from the first spike of a burst to the first spike of the next burst in the train. To exclude possible effects of burst/multiplet duration on the interval between bursts, and thus on the variability index, we only compared bursts of similar duration. For cells in which burst duration was highly variable, we restricted ourselves to a range of durations in which there was no correlation $(p>0.1)$ between burst duration and the interval between bursts. A similar approach was used to quantify the variability of interspike intervals within a burst: SD of the interval between the first and second spike in a series of bursts was divided by the mean of the interval between these two spikes.

Computational model. Membrane potential decay from the soma was simulated using an explicit model of vertebrate primary sensory neurons (Amir and Devor, 2003a) using NEURON software (version 4.2.1; www.neuron.yale.edu) (Hines and Carnevale, 1997). Briefly, in the model, the soma gave rise to an unmyelinated initial segment that was followed by four short myelinated internodes ("stem axon") ending at the T-junction (see Fig. 5A). Distal to the T-junction along both the peripheral and central axon branches, the first three internodes were short, and these were followed by 30 consecutive internodes of "normal" length for a total of 33 internodes.

Data for nodes and equations for the nodal action potential are based on measurements from toad peripheral myelinated axons (Xenopus laevis) by Frankenhaeuser and Huxley (1964) as provided in the fh.mod file in the EXAMPLES directory of NEURON. These parameters were adopted for modeling the soma and initial segment with some modifications (Amir and Devor, 2003a). Prolonged depolarizing steps (usually $200 \mathrm{~ms}$ ) or sinusoidal oscillations were injected into the soma or axon under current-clamp conditions, and recordings were made in the soma 
at nodes along the stem axon, the peripheral and central axonal branches, and the T-junction. We used the Crank-Nicholson second-order accuracy method for integration $(d t=0.01 \mathrm{~ms})$. Temperature was $20^{\circ} \mathrm{C}$.

All means are given \pm SD. Statistical comparisons were based on two-tailed $t$ tests, the Kolmogorov-Smirnov (K-S) test, Fisher exact probability test, and Mann-Whitney $U$ test with a significance criterion of $p=0.05$.

\section{Results \\ Ectopic firing recorded in DRG neurons}
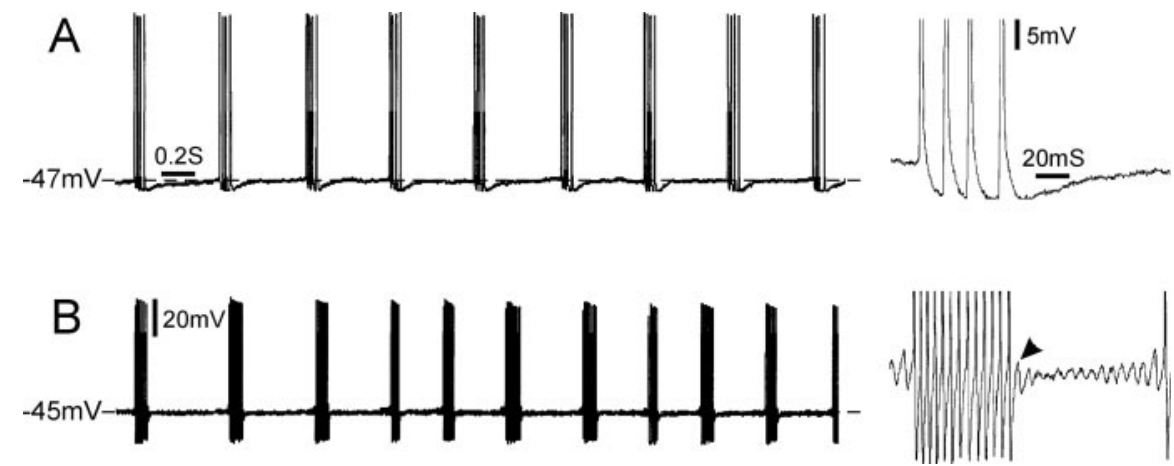

Figure 1. Clock-like versus irregular bursting. $\boldsymbol{A}$, This cell fired multiplet bursts consisting of four spikes per burst, with clock-like regularity in the presence of 4-AP. A single burst is shown on an expanded time scale and gain on the right. Bursts were not preceded by subthreshold oscillations and were not followed by a DAP. Note the regular interval between multiplets (variability index, 0.02). $\boldsymbol{B}$, Burst firing in a different cell was triggered by subthreshold oscillations and maintained by DAPs ( $\boldsymbol{B}$, right arrowhead). The interval between bursts was not as regular as the cell in $\boldsymbol{A}$ (variability index, 0.3 ). Both cells had a highly regular ISI within bursts (variability index: $\boldsymbol{A}, 0.08 ; \boldsymbol{B}, 0.06)$. Calibration bars refer to both $\boldsymbol{A}$ and $\boldsymbol{B}$.

Table 1. Effect of 4-AP on biophysical parameters of DRG neurons

\begin{tabular}{llllll}
\hline & $V_{\mathrm{r}}(\mathrm{mV})$ & $R_{\text {in }}(\mathrm{M} \Omega)$ & Spike amplitude $(\mathrm{mV})$ & Spike duration $(\mathrm{ms})$ & AHP amplitude $(\mathrm{mV})$ \\
\hline Before 4-AP & $-59.5 \pm 8.2$ & $19.8 \pm 12.4$ & $86.0 \pm 12.18$ & $1.2 \pm 0.9$ & $13.0 \pm 1.9$ \\
After 4-AP $^{a}$ & $-40.7 \pm 8.2$ & $31.2 \pm 7.6$ & $95.1 \pm 11.05$ & $2.0 \pm 0.9$ & $6.6 \pm 3.1$ \\
Difference $^{a}$ & $p<0.05$ & $p=0.06$ & $p<0.02$ & $p<0.001$ & $p<0.005$ \\
Cells sampled & $n=6$ & $n=5$ & $n=13$ & $n=13$ & $n=8$ \\
\hline
\end{tabular}

${ }^{a}$ Based on paired two-tailed $t$ test. arization. There were no exceptions (Amir et al., 1999; Liu et al., 2000). We now report that after bath application of 4 -AP, ectopic firing may be recorded in the DRG in the absence of subthreshold oscillations.

Repetitive firing in the DRG in the absence of oscillations In a sample of 16 DRG A-neurons tested in drug-free medium, none had subthreshold oscillations at $V_{\mathrm{r}}$, and only one developed oscillations that triggered spike bursts when depolarized. Bath application of 4-AP elicited oscillations and firing in an additional two. However, repetitive firing in the absence of oscillations appeared in an additional eight $\left(\right.$ at $V_{\mathrm{r}}$ ). In subsequent cell impalements in these ganglia (in eight cells), five additional neurons with ongoing spike discharge but no oscillations were encountered. Overall, 18 of 24 (75\%) neurons sampled in the presence of 4-AP fired at $V_{\mathrm{r}}, 13$ of 18 without oscillations (72\%). This compares to 15 of 290 neurons $(5 \%)$ that fired repetitively at $V_{\mathrm{r}}$ in both control and sciatic-injured preparations in vitro, in the absence of 4-AP ( $p<0.00001$; Fisher's test), none without oscillations $(0 \% ; p<0.00005)$ (Amir et al., 1999, 2002a). The observation of repetitive spike discharge in the absence of subthreshold oscillations challenges our previous conclusion that oscillations are a sine qua non of ectopia.

Figure 1 shows examples of repetitive spiking recorded in DRG cells that did and did not have subthreshold oscillations. Those without oscillations (Fig. $1 A$ ) had a distinctive firing pattern seen previously in vivo but only rarely in vitro. Specifically, almost all (12 of 13) discharged with a regular (tonic) clock-like ISI. Two cells fired singlet spikes in this manner, but in most (10 of 12), firing was in multiplets of 2, 3, 4, or more closely spaced spikes separated by a fixed and much longer intermultiplet interval (Fig. $1 A$ ). The repetition rate of singlet and multiplet spikes was $2-10 \mathrm{~Hz}$ (mean, $4.2 \pm 2.5 \mathrm{~Hz}$ at $V_{\mathrm{r}}$ ), and the variability index was $0.05 \pm 0.03$ (range, $0.02-0.1 ; n=12$ ), indicating regular clock-like activity. The remaining cell fired bursts at irregular intervals (variability index, 0.4 ), very much like cells in which

burst firing is triggered by subthreshold oscillations (Fig. $1 B$ ) (variability index, $0.28 \pm 0.15 ; n=13 ; p<0.001$ compared with those with clock-like bursts). In both types of cells, ISI within bursts was highly regular (variability index, $0.07 \pm 0.08, n=7$ for nonoscillating cells; $0.04 \pm 0.01, n=14$ for oscillating cells).

Other changes induced by 4-AP (Table 1) included depolarization, increased $R_{\text {in }}$, increased spike height and duration, and the appearance of an inflection on the falling phase of the spike of A-neurons that previously had no inflection (in 7 of 21 cells). Likewise, the amplitude of the postspike hyperpolarization was reduced, and its peak was delayed, blurring the distinction originally apparent in some cells between brief and slow AHP phases (five of five cells). These changes are consistent with previous reports of $\mathrm{K}^{+}$channel $\left(I_{\mathrm{A}}\right)$ block in primary afferent somata (Puil et al., 1989; Hille, 2001; Amir et al., 2002b), and they confirm cellular access of the 4-AP.

In a previous study, we determined why block of $\mathrm{K}^{+}$conductances with drugs such as 4-AP has facilitatory effects on spike electrogenesis in DRG neurons (Amir et al., 2002b). Our aim in the present study was to understand ectopic electrogenesis in the absence of subthreshold oscillations.

\section{Ectopic firing in the absence of subthreshold oscillations is triggered outside of the DRG}

The nerve end neuroma as pacemaker

Consider the neuron illustrated in Figure 2. At $V_{\mathrm{r}}(-58 \mathrm{mV})$, this cell fired irregularly spaced singlet action potentials at $\sim 10 \mathrm{im}$ pulses/s (Fig. $2 B, C$ ). No oscillatory behavior was present during the intervals between spikes, and spikes arose from a flat baseline rather than from the depolarizing phase of oscillatory sinusoids. Hyperpolarization eliminated the soma spike. However, unlike cells of which spiking originates in somatic subthreshold oscillations (Amir et al., 1999), hyperpolarization left a small unitary potential (Fig. 2Biv) ("m-spike;" $-70 \mathrm{mV}$ ), the frequency of 
A
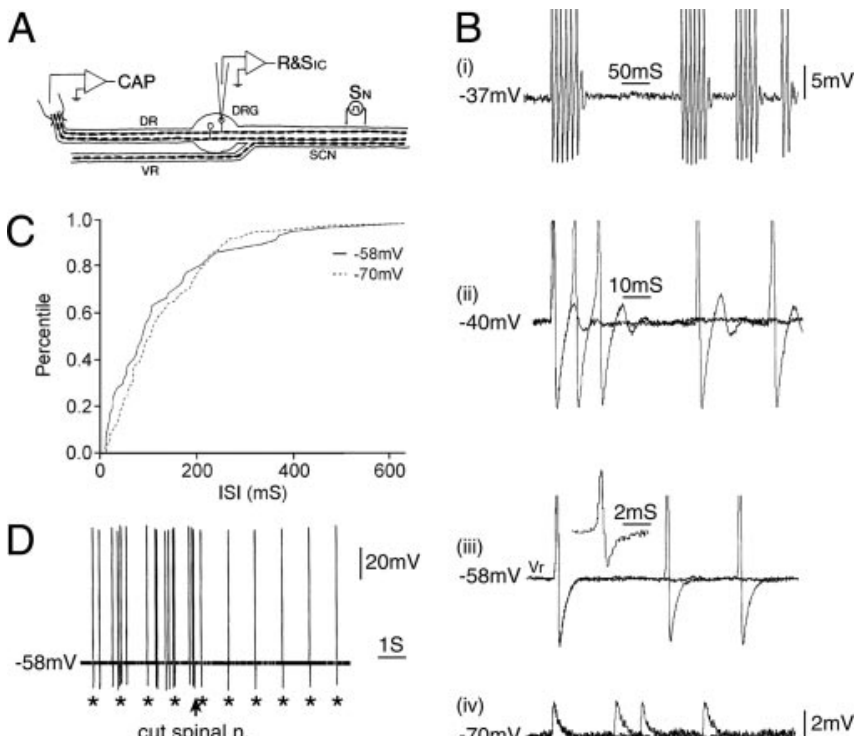

cut spinal $\mathrm{n}$.
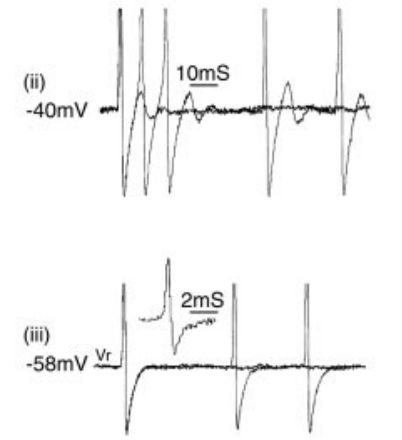

(iv)

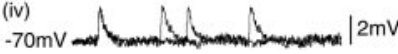

Figure 2. Spontaneous discharge originating in the axon rather than in the cell soma. $\boldsymbol{A}$, The experimental setup. CAP, Suction electrode recording compound action potential; $R \& S_{I C}$ intracellular recording micropipette; $S C N$, sciatic nerve; $S_{N}$, stimulating electrode on nerve. $\boldsymbol{B}$, This neuron fired spontaneous spikes at $V_{r}(-58 \mathrm{mV})$ but did not have subthreshold oscillations. Depolarization induced the appearance of a DAP after each spike, which sometimes triggered subsequent spikes, resulting in burst firing (traces at -37 and $-40 \mathrm{mV}$ ). Hyperpolarization to $-70 \mathrm{mV}$ caused failure of soma spikes, leaving only residual (axonal) m-spikes. Thus, the soma spikes (singlets and bursts) at more depolarized potentials were triggered by action potentials of axonal origin. These axonal spikes also propagated into the L5 DR as demonstrated by the spike-triggered average of the signal recorded on the DR suction electrode (inset adjacent to the trace at $-58 \mathrm{mV}$ ). C, Consistent with this interpretation, the frequency of the singlet spikes at $-58 \mathrm{mV}$ matched that of $\mathrm{m}$-spikes at $-70 \mathrm{mV}$ (and spike bursts at $-37 \mathrm{mV}$ ). The plot shows the cumulative distribution of singlet spike and m-spike ISI ( $d=0.16 ; p>0.2 ; \mathrm{K}-\mathrm{S}$ test; http://www.physics.csbsju.edu/stats/KS-test.html). D, Electrical stimulus pulses delivered to the spinal nerve ( $1 \mathrm{~Hz}$; asterisks) triggered soma spikes. These summed with the spontaneously occurring spikes. Transection of the spinal nerve just distal to the stimulating electrode (arrow) eliminated the spontaneous spikes but not the stimulation-evoked spikes.

which was identical to that of the full soma spike ("s-spike") that had been quenched (Fig. 2C). This indicates that the firing originated in the axon and only secondarily invaded the soma (Ito, 1959).

When the soma was depolarized, the invading spikes began to develop a brief DAP (Fig. 2 Bii, $-40 \mathrm{mV}$ ). The amplitude of this DAP increased with additional depolarization until it was big enough to trigger a second spike, and then a third, eventually yielding spike bursts (Fig. $2 B i,-37 \mathrm{mV}$ ). Bursting was irregular (variability index, 0.55 ), and burst repetition rate averaged 10/s, as with the original singlet spikes. Acute transection of the spinal nerve $8 \mathrm{~mm}$ from the DRG eliminated the spontaneous firing, although the cell continued to respond to electrical stimulus pulses delivered to the nerve just proximal to the cut (Figs. 2D, 3).

Together, these observations indicate that the original spontaneous singlet spiking arose at the cut end of the sciatic nerve (Michaelis et al., 1995) and that, when the soma was depolarized, the invading axon spike triggered DAP-evoked spike bursts that originated in the cell soma. Note that under these conditions, individual bursts were of hybrid origin, the first spike in each burst being axonal and subsequent spikes somatic. Because the spikes that set the pace of bursting (i.e., the first spike in each burst) came from the axon, far from the soma, shifts of the somatic $V_{\mathrm{m}}$ (depolarization or hyperpolarization) did not affect the frequency of singlet spikes or of bursting, which remained fixed at 10/s. But such shifts did affect somatic bursting. Of the 13 neu-
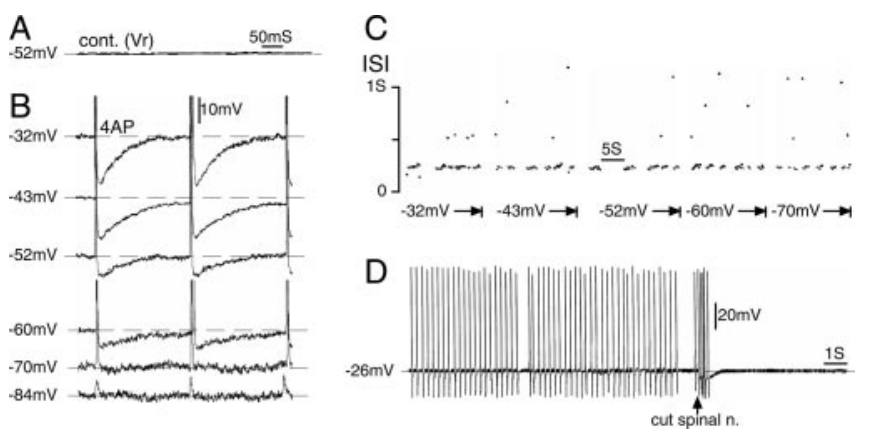

Figure 3. Repetitive firing after 4-AP application originated in the nerve-end neuroma. $\boldsymbol{A}$, This neuron, which was silent at $V_{r}(-52 \mathrm{mV})$, began to fire bursts (with occasional misses) after 4-AP application (1 mm). cont., Control. $B$, Shifting the membrane potential between -32 and $-84 \mathrm{mV}$ had no effect on the ISI within a burst, although the AHP became smaller with hyperpolarization, and eventually the soma spike blocked, leaving residual $\mathrm{m}$-spikes (at $-84 \mathrm{mV}$ ). C, The voltage independence of firing frequency is also illustrated in this ISI dot raster plot. Dots above the main scatter at $I S I=215 \mathrm{~ms}$ (corresponding to a firing frequency of $4.7 \mathrm{~Hz}$ ) are integer multiples of the basic ISI, indicating that they represent spikes missed within the burst (Matzner and Devor, 1993). D, Transection of the spinal nerve (arrow) eliminated the spiking, affirming its origin in the distal part of the axon.
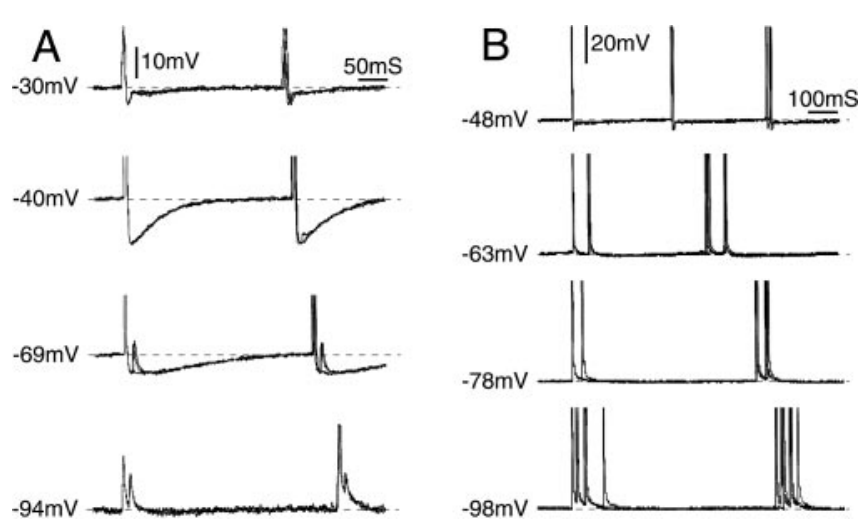

Figure 4. Evidence for ectopic electrogenesis in the neuronal stem axon or T-junction. $\boldsymbol{A}$, Tonic discharge emerged in this neuron after application of 4-AP. Subthreshold oscillations are absent; the spikes were triggered from outside of the cell soma (i.e., from the axon). However, the interval between adjacent spikes in the train (ISI) varied with the somatic membrane potential (range, -30 to $-94 \mathrm{mV}$ ), indicating that the axonal site of spike initiation was within a few space-constants of the soma (hence the stem axon or T-junction). When the cell was hyperpolarized $(-94 \mathrm{mV})$, soma spikes failed, leaving residual m-spikes. Note that at the axonal site of electrogenesis, firing was frequently in doublets (interval, $15 \mathrm{~ms}$ ) but only at more hyperpolarized potentials. The first spike of each doublet triggered a soma spike; the second appeared as an m-spike within the AHP of the soma spike. $\boldsymbol{B}$, In a second neuron that also fired tonically after 4-AP application, shifting $V_{m}$ in the hyperpolarizing direction (from -48 to -98 $\mathrm{mV}$ ) caused a shift from singlet to multiplet discharge and a progressive increase in the interval between bursts. ISI within multiplets, in contrast, decreased with hyperpolarization, and the number of spikes per multiplet increased. All traces show three superimposed sweeps.

rons that fired repetitively in the absence of subthreshold oscillations, eight behaved in this way, suggesting that their pacemaker activity originated in the cut nerve end (see below).

\section{Electrogenesis at the T-junction}

In the remaining five DRG neurons, firing frequency was modulated by hyperpolarizing and depolarizing shifts of somatic $V_{\mathrm{m}}$ (Fig. 4). In these neurons, spike initiation occurred outside of the cell soma but close enough to the soma that shifts in somatic membrane potential could affect rhythmogenesis. Based on considerations presented below, we conclude that firing in these neurons originated at the axonal $\mathrm{T}$-junction. 


\section{The maintenance of ectopic multiplet bursts and spike trains}

Bursting and tonic firing is normally maintained by DAPs Consistent with previous reports, in the neurons of which discharge originated in somatic subthreshold oscillations $(n=5)$, bursts were maintained by DAPs. Somatic depolarization decreased the latency of the DAPs, thus decreasing ISI within bursts and increasing firing rate (Amir et al., 2002a; Liu et al., 2002).

One of the five cells showed an instructive variant. Oscillation sinusoids triggered clock-like tonic firing of doublet spikes. The first spike in each doublet was triggered when $V_{\mathrm{m}}$ rebounded from a prolonged postdoublet AHP. This depolarizing rebound might actually be considered a type of extended DAP. The interval between doublets, which was voltage sensitive, was $218.7 \pm$ $18.8 \mathrm{~ms}$ at $-64 \mathrm{mV}$ (variability index, 0.09), whereas the interval between spikes within the doublet was $9.7 \pm 1.0 \mathrm{~ms}$ (variability index, 0.1) Although the first spike in each doublet was triggered in this manner, the second spike was not triggered by a conventional somatic DAP. We know this because the cell did not generate short-latency postspike DAPs when stimulated, or on axonal spike invasion, and because depolarizing the soma increased the interval between the doublet spikes, eventually eliminating the second spike altogether. Depolarization is known to decrease DAP latency (Amir et al., 2002a). We infer that the first spike of each doublet was generated in the soma, whereas the second was generated at the T-junction (see below). This situation, in which component spikes of a burst are generated at different locations, is apparently not uncommon (Fig. 2B) (see below).

Bursts can be maintained in the absence of somatic DAPs

As noted above, in neurons that fired repetitively in the absence of oscillations, firing was triggered at sites outside of the cell soma (i.e., at the neuroma or the T-junction). The clock-like firing of these neurons indicates that their basic firing rhythm, the interval between multiplet bursts, was set by DAPs rather than by subthreshold oscillations. The variability index of the clock-like bursts, $0.05 \pm 0.03$, was very close to that of ISIs within bursts maintained by somatic DAPs $(0.04 \pm 0.01 ; n=14 ; p>0.2)$ but far less than that of bursts triggered by somatic oscillations $(0.28 \pm 0.15 ; n=13 ; p<0.001)$. The multiplet bursts generated by 10 such neurons were also maintained in the axon rather than in the soma; none of the spikes were preceded by a DAP or any other generator prepotential visible in the soma. Moreover, the variability index of ISI within multiplets $(0.07 \pm 0.08 ; n=7)$ was close to that of somatic DAPs $(0.04 \pm 0.01 ; p>0.2)$. The nature of the axonal pacemaker potential that triggered the multiplet bursts, and the potential that determined the ISI of spikes within multiplets, is discussed below.

\section{Ectopic firing in the absence of subthreshold oscillations is maintained outside of the DRG}

\section{Firing maintained within the neuroma}

In 8 of 13 neurons that fired repetitively in the absence of oscillations, shifting $V_{\mathrm{m}}$ failed to affect the interval between multiplets. Moreover, in seven of the eight, shifting $V_{\mathrm{m}}$ had no effect on ISI within the bursts. In the example shown in Figure 3, $B$ and $C$, spikes within a burst arrived at intervals of $215 \mathrm{~ms}$ ( 4.7 impulses/ $\mathrm{s})$. ISI was unaffected by shifts in $V_{\mathrm{m}}$ of $>50 \mathrm{mV}$, and hyperpolarization (to $-84 \mathrm{mV}$ ) blocked the s-spikes revealing $\mathrm{m}$-spikes with the identical ISI. Insensitivity of ISI between and within bursts indicates that bursts are both triggered and maintained far from the soma. Silencing of firing after a brief "injury discharge" by resection of the nerve end (Fig. 3D) suggests that the pacemaker location is in the neuroma. In the remaining neuron, changing $V_{\mathrm{m}}$ had no effect on the interval between multiplets, but it did affect the ISI within multiplets and the number of spikes per multiplet. Thus, although multiplets were triggered in the cut nerve end, subsequent spikes within a multiplet were triggered at an axonal location nearer to the soma. This location is probably the T-junction (see below).

\section{Firing triggered and maintained at the T-junction}

In some neurons that fired without subthreshold oscillations, hyperpolarization increased the interval between multiplets and also affected ISI within multiplets (five neurons) (Fig. 4). Voltage dependence suggests that the processes of burst triggering and of maintenance occurred electrically close to the cell soma, a distance of no more than a few space constants. The only obvious candidate site is the axonal T-junction, a location where there are several structural specializations that favor spike electrogenesis, including a large junctional node of Ranvier and closely spaced perijunctional nodes (Ito and Takahashi, 1960; Ha, 1970; Spencer et al., 1973).

Interestingly, shifting $V_{\mathrm{m}}$ did not change the ISI within bursts in the manner that might have been expected from the effect of such shifts on interburst interval. In three of the five neurons, rather than hyperpolarization increasing ISI and hence reducing within-burst firing rate, the opposite effect was observed: hyperpolarization decreased the within-burst ISI and increased firing rate. The number of spikes per burst also increased (Fig. $4 A, B$ ). In a fourth neuron, changing $V_{\mathrm{m}}$ had complex effects. At first, hyperpolarization increased ISI and decreased the number of spikes per burst. However, additional hyperpolarization decreased ISI and increased the number of spikes per burst. In the final cell, the effect of $V_{\mathrm{m}}$ on bursting could not be determined. The likely explanation of this behavior is discussed below.

To test the hypothesis that voltage dependence of bursting and within-burst ISI in cells without subthreshold oscillations reflects electrogenesis at the T-junction, we used our explicit simulation of a vertebrate DRG neuron (see Materials and Methods) (Amir and Devor, 2003a). Step depolarizations were delivered at the cell soma, and measurements of the steady-state potential were taken along the length of the axon, including at the T-junction. Shifting $V_{\mathrm{m}}$ at the soma yields a change of $20-25 \%$ in $V_{\mathrm{m}}$ at the T-junction (Fig. 5). For example, a $25 \mathrm{mV}$ depolarization in the soma shifted the T-junction $V_{\mathrm{m}}$ by $\sim 6 \mathrm{mV}$. A depolarizing shift of this magnitude is expected to noticeably increase firing frequency at the T-junction-encoding site [Amir et al. (2002b), their Fig. 4C; Matzner and Devor (1992)]. In contrast, the same $25 \mathrm{mV}$ shift produced only a negligible $(<0.1 \mathrm{mV})$ change in membrane potential beyond $10 \mathrm{~mm}$ along the peripheral axon. Because the sciatic nerve end was usually $>10 \mathrm{~mm}$ from the DRG, shifting $V_{\mathrm{m}}$ is not expected to alter electrogenesis in neuroma endings.

\section{Multiple discharge sources in a single fiber and interactions}

Spikes generated at multiple sources may interact to generate complex discharge patterns. Figure 2 illustrated the ability of spontaneous discharge generated at one site (axon) to trigger bursts at another (DRG). In the example in Figure $6 \mathrm{~A}$ (left), ongoing spike activity consisted of interleaved spikes, some of which originated in the DRG (unmarked) and some in the axon (marked with arrowheads). As above, the distinction is based on whether the spike emerges from an oscillation sinusoid or DAP (DRG origin) or from a flat baseline (axonal origin). Here too, spikes originating in the axon triggered subsequent spikes, or 


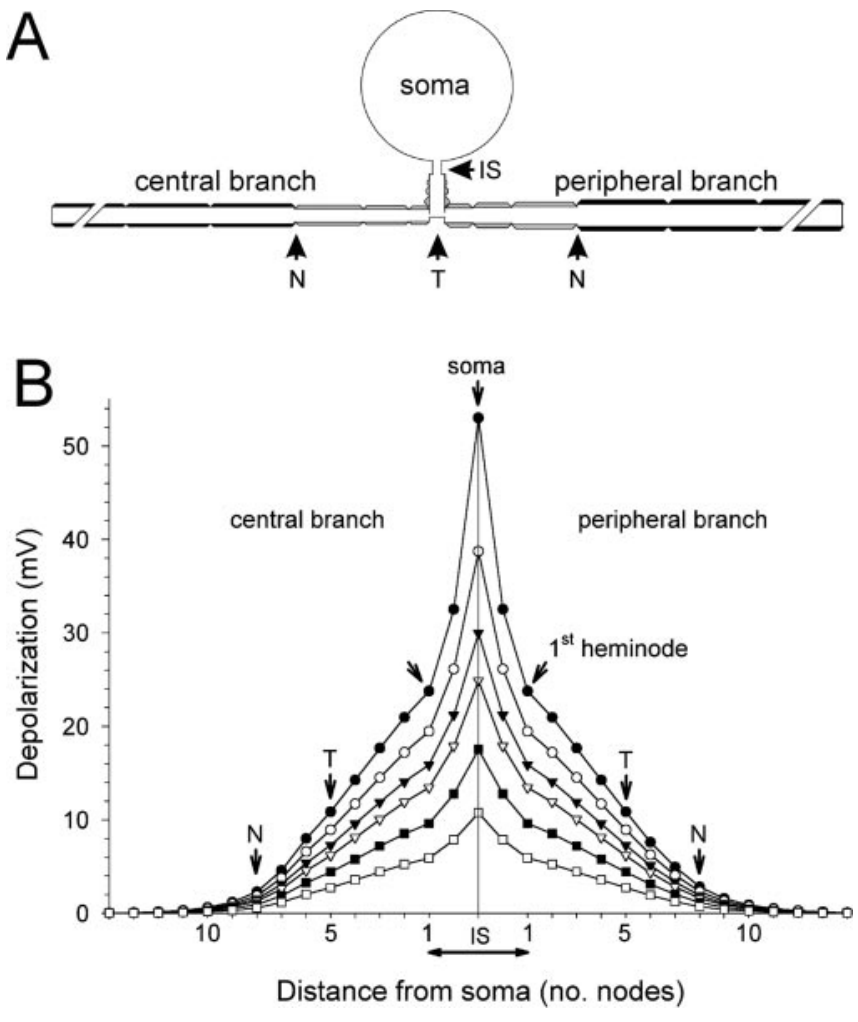

Figure 5. Simulation of the membrane potential decay from the soma to the T-stem and the central and peripheral branches. $\boldsymbol{A}$, A sketch of the cell model. B, Depolarizing pulses $(200 \mathrm{~ms})$ were applied to the soma (current clamp), and the level of resultant depolarization at steady state was recorded in subsequent nodes along the T-stem and the central and peripheral axonal branches. IS, Initial segment, the unmyelinated part of the T-stem; T, T-junction. The three internodes between $T$ and $\mathrm{N}$ in both peripheral and central branches were short and had fewer myelin wraps. Subsequent internodes had "normal" parameters (Amir and Devor, 2003a).

spike bursts, in the DRG. A small shift in $V_{\mathrm{m}}$ was enough to abolish the interaction; hyperpolarization of only $3 \mathrm{mV}$ (from -42 to $-45 \mathrm{mV}$ ) was enough to block electrogenesis in the soma (oscillations and DAPs) leaving only axonal discharge (Fig. 6A, right). Interactions between multiple sources can also be suppressive. In the cell illustrated in Figure $6 B$, a tonic spike train originated in the axon (T-junction). A brief burst of spikes, generated either by tetanic stimulation of the nerve or step depolarization of the soma (asterisk), silenced the tonic firing for several seconds. We reported previously similar results in vivo (Lisney and Devor, 1987).

\section{Afterdischarge bursts recorded in the DRG}

Afterdischarge is normally triggered by somatic DAPs

Some DRG neurons respond to single brief stimulus pulses applied to the soma or axon with a short burst of spikes rather than with a single spike; this is afterdischarge (Lisney and Devor, 1987; Devor and Wall, 1990; Gottrup et al., 2003). Normally, the second, third, and subsequent spikes forming an afterdischarge burst are generated within the soma by DAPs (Fig. 7A) (Amir et al., 2002a). However, in preparations treated with 4-AP, afterdischarge was sometimes observed in neurons that did not generate a somatic DAP.

Afterdischarge can occur in the absence of somatic DAPs

We examined afterdischarge in 10 cells before and after applying 4-AP. In the control bath solution, all 10 responded to single-

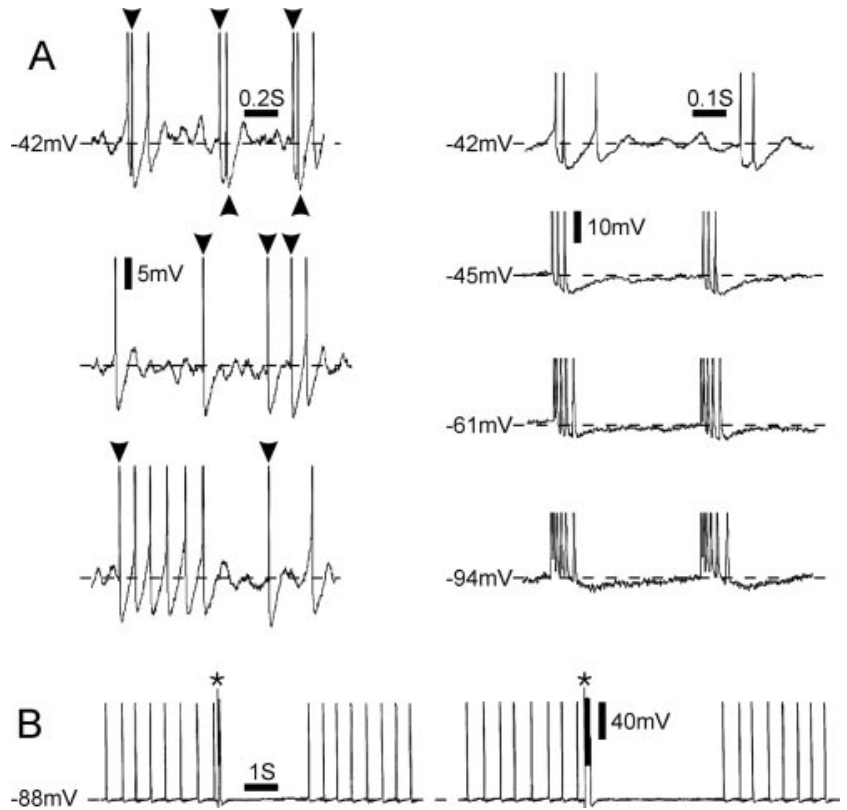

Figure 6. Interaction among alternative sources of repetitive firing. A, Left, Spontaneous activity of singlets and short bursts recorded from the soma of a DRG neuron $\sim 6$ min after 4-AP application. This cell exhibited both oscillations and DAPs only after 4-AP superfusion. Some of the spikes were generated in the soma by oscillations and DAPs (unmarked spikes), whereas others (arrowheads) invaded the soma after generation elsewhere. Spikes are truncated. Right, Hyperpolarization abolished oscillations, DAPs, and resultant soma spikes, leaving only invading spikes. These were generated in a tonic pattern with multiplets. After additional hyperpolarization, the ISI within a multiplet was gradually decreased, and the number of impulses increased; however, intermultiplet interval was unaffected. $\boldsymbol{B}$, Tonic spontaneous activity in the absence of oscillations and DAPs, indicating that the firing was generated outside the soma. A $100 \mathrm{~ms}$ (left) or $200 \mathrm{~ms}$ (right) suprathreshold depolarizing pulse applied via the recording micropipette (asterisks) generated a burst of soma spikes and then abolished firing for several seconds, too long to be accounted for by spike collision. The spike burst apparently silenced electrogenesis at the axonal pacemaker site.
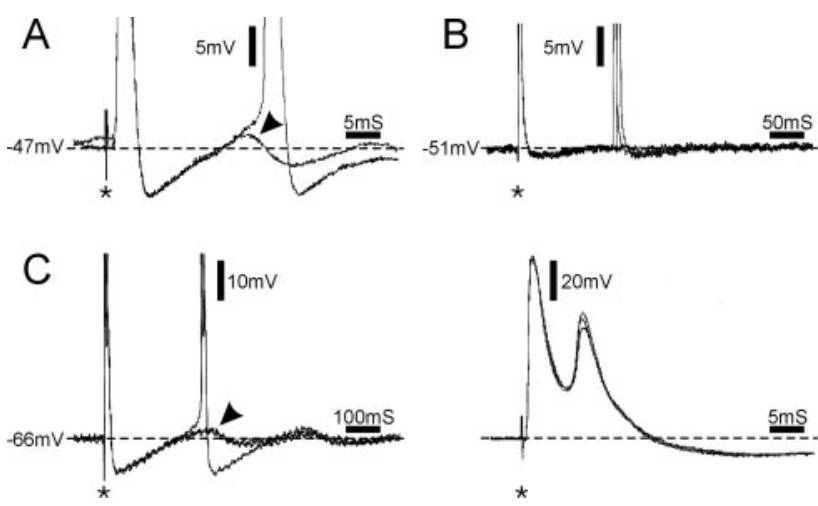

Figure 7. Afterdischarge triggered by stimulus pulses applied to the nerve $(A, C)$ or the soma $(\boldsymbol{B} ;$ asterisks) in the presence of 4-AP. $\boldsymbol{A}-\boldsymbol{C}$ show three different neurons. $\boldsymbol{A}$, Afterdischarge maintained by a postspike DAP (arrowhead). $\boldsymbol{B}$, Afterdischarge triggered in the absence of a DAP, long after recovery from a prolonged AHP (3 traces; in 1 trace, afterdischarge was not evoked). $C$, In this neuron, axonal stimulation evoked two bursts of doublets. The first spike in the second doublet was triggered by a DAP (C, left, arrowhead). The second spike, however, appears during the falling phase of the first spike as seen on a faster time scale ( $\boldsymbol{C}$, right). In all panels but $\boldsymbol{C}$ (right), spikes are truncated. Two sweeps are superimposed in $\boldsymbol{A}$, and three sweeps are superimposed in $\boldsymbol{B}$ and $\boldsymbol{C}$.

pulse stimulation with single spikes. Only one showed a DAP (at $V_{\mathrm{r}}$ ). This is typical of normal DRG neurons (Amir et al., 2002a). After 4-AP application, however, five cells began to show afterdischarge bursts in response to stimulus pulses despite the con- 
tinued absence of a visible DAP. Subsequent impalements confirmed that afterdischarge had now become common. In the next eight cells examined, all had afterdischarge. In two, afterdischarge was maintained by DAPs as expected (Fig. 7A), but in the others, no DAP was present (Fig. $7 B, C$ right). Thus, afterdischarge bursts were observed in the absence of DAPs in 11 cells. In these cells, the bursts were maintained at locations outside of the cell soma.

The high incidence of afterdischarge in the present study (13 of 18 cells) was almost certainly induced by 4 -AP, as in control and axotomized preparations at $V_{\mathrm{r}}$ without 4-AP, it was very rare ( 9 of 315 cells; $p<0.0001$; Fisher's test) (Lisney and Devor, 1987; Devor and Wall, 1990; Amir et al., 2002a). Afterdischarge usually consisted of short bursts (two to four spikes) with a brief ISI $(8.3 \pm 1.7 \mathrm{~ms} ; n=7)$. This is similar to afterdischarge bursts seen in cells studied in normal bath solution (7.2 $\pm 1.2 \mathrm{~ms} ; p>0.2$; Mann-Whitney) (Amir et al., 2002a). In some of the cells, however, the ISI was much longer (15 and $23 \mathrm{~ms}$ in two cells; $227.2 \pm 111.9 \mathrm{~ms}$ in four cells).

Three cells (all axotomized) were unusual in that stimulus pulse-induced afterdischarge took the form of repetitive multiplets (two to five spikes per multiplet) that lasted for an extraordinary length of time, tens of minutes in two of the three (Fig. 8). The remaining cell responded to single stimulus pulses with a pair of doublet spikes. Although the first doublet was triggered directly by the stimulus, the second doublet was triggered by a soma DAP (Fig. 7C, left). Interestingly, the second spike in both doublets emerged in the absence of a noticeable DAP (Fig. 7C, right), implying that it originated in the axon.

\section{Relationship between spontaneous and afterdischarge bursting}

Both in vivo and in vitro spontaneous firing and afterdischarge are commonly recorded in the same cells (Devor and Wall, 1990; Amir et al., 2002a). A stimulus pulse applied during a silent period in a spontaneous burster typically triggers an afterdischarge that, in turn, resets the spontaneous firing cycle, entraining it to the stimulus pulse (Lisney and Devor, 1987).

In the present study, most of the DRG neurons that showed afterdischarge also fired spontaneously (11 of 13), whereas no spontaneous firing was seen in neurons that had no afterdischarge (five neurons tested under the same conditions; $p<0.005$ ). Spontaneous firing and afterdischarge bursts appear to originate at the same sites and by similar mechanisms. In 2 of the 11 neurons, spontaneous bursts were maintained by DAPs, indicating a source in cell soma. Afterdischarge bursts in these cells also originated in the soma. In the remaining nine cells, both spontaneous firing and afterdischarge bursts originated outside of the DRG (Fig. 7, compare $A$ and $B$ ). Additional evidence of a common origin comes from a comparison of the ISI within the spontaneous multiplets versus afterdis-
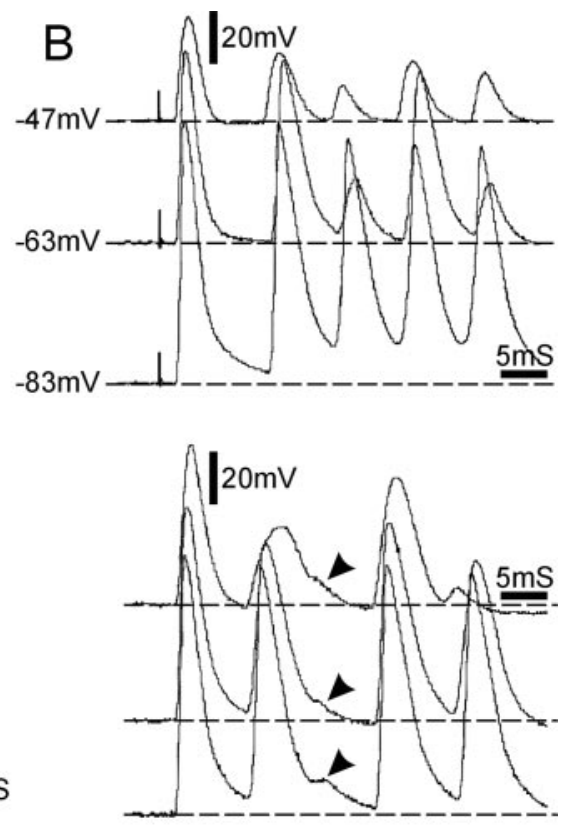

$5 \underline{\underline{0 m S}}$

$3 \mathrm{~min} . \quad 8 \mathrm{~min}$.

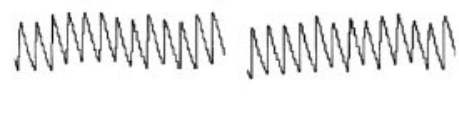

Figure 8. Afterdischarge of prolonged rhythmic multiplets after chronic nerve lesion in the presence of 4-AP. $\boldsymbol{A}$, The experiwas aborted (arrowheads). D, Firing rate plot shows that this afterdischarge burst pattern persisted for many minutes after the initiating stimulus pulse (asterisk). Imp./s, Impulses per second.

charge ISI. In all cases, these were nearly identical (slope of the regression line, $0.496 ; r=0.99 ; p<0.0001)$. The interval between the spontaneous multiplets, in contrast, was not predictive of the afterdischarge ISI $(r=0.48 ; p>0.2$; both plots based on eight cells with spontaneous firing and afterdischarge).

\section{Discussion}

Modification of the excised whole DRG preparation by the addition of 4-AP to the bath yielded ectopic spike activity that was not related to somatic oscillations or DAPs. A variety of approaches established that these spikes arise in the axon, either at the site of axotomy (neuroma) or in the region of the T-junction. Characteristics of the discharge suggest that electrogenic processes in the axon are similar to those in the cell soma.

\section{Multiple sites of ectopic impulse initiation}

Spike generation requires some form of prepotential. In the soma, this role was filled by the depolarizing limb of oscillatory sinusoids and DAPs. Discharge rate increased continuously on depolarization and was quenched when the soma was hyperpolarized. Cells in which spike generation occurred distally along the axon were characterized by the absence of oscillations, DAPs, or any other prepotential visible in the soma, insensitivity of firing rate to somatic $V_{\mathrm{m}}$, and inability to quench the firing by 
somatic hyperpolarization. In these cells, discharge could often be eliminated by blocking or severing the spinal nerve, indicating that it originated at the neuroma end. Finally, in a third class of cells, no prepotential was visible, but firing rate was (modestly) sensitive to somatic $V_{\mathrm{m}}$. Based on computer simulations, we conclude that spike origin was at the T-junction, the only site electrically close to the soma that has structural specializations that might sustain electrogenesis (Ha, 1970; Spencer et al., 1973).

Our inability to record intra-axonally from fine fiber endings in the neuroma, or from the T-junction axon, precludes definitive identification of the electrogenic process at these ectopic pacemaker sites. Nevertheless, the similarity of firing patterns, no matter where the spike originated, leads us to infer that the burst and tonic discharges that originated outside of the soma are also triggered by subthreshold oscillations (Kapoor et al., 1997) and maintained by axonal DAPs (Fig. 7C) (but see below). This inference is strengthened by the observation that afterdischarge bursts have similar properties, whether generated in the soma or in the axon. Axonal oscillations and DAPs are not expected to be visible in somatic recordings. At resting membrane potential, oscillations and DAPs are usually $\leq 3 \mathrm{mV}$ in amplitude (Amir et al., 1999, 2002a; Liu et al., 2000). Simulation showed that such signals, if present in the neuroma, would be so attenuated in somatic recordings as to be undetectable, their amplitude falling within the baseline noise. Even if originating closer, at the T-junction, oscillations would be attenuated by between $80 \%$ (for oscillation frequency; $\mathrm{f}=100 \mathrm{~Hz}$ ) and $65 \%$ (for $\mathrm{f}=5 \mathrm{~Hz}$ ). This would render them undetectable in the soma in almost all cases.

\section{Ectopia in soma versus axon}

Although 4-AP was used at relatively high concentration (1 mM), it had relatively minor effects on electrogenesis in the cell soma. In vivo, also, 4-AP preferentially induces spike discharge in demyelinated axons, neuroma endings, and developing and regenerating axons (Kocsis et al., 1982; Devor, 1983; Bowe et al., 1985; Targ and Kocsis, 1986; Eng et al., 1988; Honmou et al., 1994; Lees, 1996; Cabanes et al., 2003). The difference between axon and soma is probably attributable to the specific $\mathrm{K}^{+}$conductances targeted by the drug. 4-AP is relatively selective for the fastinactivating $\mathrm{K}^{+}$conductance $I_{\mathrm{A}}$ (Bostock et al., 1981; Castle et al., 1989; Strong, 1990; Safronov et al., 1996; Hille, 2001). $I_{\mathrm{A}}$ is expressed in axons, but it is also present in large-diameter DRG somata (Gold et al., 1996; Everill et al., 1998). Why, then, was spike electrogenesis in the soma essentially resistant to 4-AP? A likely reason is that $I_{\mathrm{A}}$ is mostly inactivated at the relatively depolarized potentials at which oscillations normally appear in the soma (Everill et al., 1998; Fedulova et al., 1998). This implies that spiking is generated at relatively hyperpolarized potentials in the axon. At $1 \mathrm{~mm}, 4$-AP also partially blocks the slowly inactivating $\mathrm{K}^{+}$conductance $I_{\mathrm{D}}$ (Everill et al., 1998; Fedulova et al., 1998). Finally, our data resolve an anomaly in observations by Puil et al. $(1988,1989)$ in trigeminal ganglion (TRG) neurons. In their study, 4-AP suppressed membrane resonance in the cell soma but nevertheless enhanced spiking. We suggest that the spiking originated at cut axon ends rather than in the TRG cell soma.

\section{Spontaneous bursting, afterdischarge, and tonic autorhythmicity}

Bursts are normally triggered by oscillation sinusoids. However, at cellular locations that generate DAPs but have no such local pacemaker, DAP-sustained discharge can be triggered by exogenous spikes. When triggered by electrical stimulus pulses, the result is afterdischarge. Bursts can also be triggered by spikes that invade from a pacemaker site elsewhere in the neuron. This is one of the modes of interaction among alternative ectopic spike sources (see below).

DAP-sustained firing is stopped by burst-induced prolonged AHP. In neurons that do not generate a prolonged AHP, DAPsustained firing may continue indefinitely. Such sustained firing, "tonic autorhythmicity," is very different from the slow, irregular firing triggered by subthreshold oscillations in neurons that fire singlet spikes. Because consecutive spikes in the train are triggered by DAPs, not intermittent threshold-crossing sinusoids, firing rate is high (typically $10-50 \mathrm{~Hz}$ ), and ISI is very regular. Tonic autorhythmicity is common in recordings from DRG neurons and neuroma endings in vivo (Devor, 1989). When quenched artificially (e.g., using pharmacological agents such as tetrodotoxin or lidocaine) (Devor et al., 1992), its restoration is dependent on a triggering spike. In the absence of such a trigger, silence is expected to persist. This bistable behavior may account for the fact that systemically applied membrane-stabilizing drugs sometimes yield relief from pain for much longer than can be expected from the half-life of the drug itself (Chaplan et al., 1995; Araujo et al., 2003; Gottrup et al., 2003).

\section{Clock-like multiplets}

Clock-like multiplet firing was the predominant discharge pattern in axons in this study. This pattern is probably attributable to an electrogenic mechanism unique to axonal pacemaker sites. In intra-axonal recordings made in the presence of 4-AP, Honmou et al. (1994) reported that stimulus pulses were followed by delayed depolarization that is distinct from the DAPs recorded in the cell soma. Delayed depolarizations, which are thought to reflect the opening of slowly activating and inactivating $\mathrm{Na}^{+}$channels, last for a few tens of milliseconds and often generate a burst of action potentials. Specific evidence of this mechanism comes from the neurons in which ISI within bursts was shortened by hyperpolarization, resulting in increased within-burst firing frequency and an increased number of spikes per burst (Fig. $4 B$ ). Hyperpolarization delays postspike DAPs and, hence, is expected to increase ISI within multiplets and suppress bursting (Amir et al., 2002a). On the other hand, hyperpolarization increases the amplitude of the delayed depolarization [Honmou et al. (1994), their Fig. 5]. Thus, in the cell soma, the pacemaker process triggers bursts maintained by DAPs, whereas in the axon, multiplets may be maintained by delayed depolarization.

\section{Interactions among multiple ectopic sources and functional implications}

The presence in a neuron of more than one site capable of ectopic electrogenesis makes possible the assembly of individual bursts from spikes that originate at several locations, interactions among pacemaker and afterdischarge sites, and complex spike patterning. A number of such cases were pointed out in the Results. For example, we observed cells in which individual spikes generated at an axonal pacemaker site invaded the cell soma and triggered somatic afterdischarge bursts. These somatic spikes, in turn, could propagate back to the axonal pacemaker site and initiate a second cycle of axonal afterdischarge and/or reset the timing of the axonal pacemaker rhythm. Such interactions can set up reciprocating, reverberating sources of ectopic discharge (Tagini and Camino, 1973; Amir and Devor, 2003b) and could account for previously unexplained complex firing patterns seen occasionally in recordings from injured nerves (Devor, 1989). Calvin et al. (1977) proposed that in dysmyelinating diseases such as multiple sclerosis, such reverberations might generate sus- 
tained cascades of extra spikes, contributing to neuropathic dysesthesias and pain. Indeed, this process might be more general in neuropathy because any nerve trauma is capable of yielding at least three ectopic pacemaker sites, the neuroma, T-junction, and soma. The present study focused on neurons with myelinated axons. This cell population contributes importantly to neuropathic pain hypersensibility in two ways. First, it includes $A \beta$ and A $\delta$ nociceptive afferents. Second, in the presence of central sensitization, activity in $\mathrm{A} \beta$ afferents yields tactile allodynia and augmented spontaneous pain (Torebjork et al., 1992; Devor and Seltzer, 1999).

The facilitation of oscillatory behavior, ectopic firing, and afterdischarge capability by $\mathrm{K}^{+}$conductance block is more than an experimental tool; it may be an important cause of ectopic hyperexcitability after axotomy. Specifically, axotomy leads to reduced expression of $\mathrm{K}^{+}$channel Kv1.2 and Kv2.1 mRNA in DRG neurons (Ishikawa et al., 1999) and reduces $I_{\mathrm{A}}$ by $65 \%$ and $I_{\mathrm{D}}$ by $60 \%$ (Everill and Kocsis, 1999). Downregulation of these $\mathrm{K}^{+}$conductances, like the application of $\mathrm{K}^{+}$channel antagonists, is expected to powerfully augment ectopic electrogenesis. Indeed, $\mathrm{K}^{+}$channel downregulation may be as important as the upregulation and acceleration of $\mathrm{Na}^{+}$conductances (Everill et al., 2001) for the facilitation of subthreshold oscillatory behavior, ectopic spiking after nerve injury, and neuropathic pain (Kocsis and Devor, 2000).

\section{References}

Amir R, Devor M (1996) Chemically-mediated cross-excitation in rat dorsal root ganglia. J Neurosci 16:4733-4741.

Amir R, Devor M (1997) Spike-evoked suppression and burst patterning in dorsal root ganglion neurons. J Physiol (Lond) 501:183-196.

Amir R, Devor M (2003a) Electrical excitability of the soma of sensory neurons is required for spike invasion of the soma, but not for throughconduction. Biophys J 84:2181-2191.

Amir R, Devor M (2003b) Extra spike formation in sensory neurons and the disruption of afferent spike patterning. Biophys J 84:2700-2708.

Amir R, Michaelis M, Devor M (1999) Membrane potential oscillations in dorsal root ganglion neurons: role in normal electrogenesis and in neuropathic pain. J Neurosci 19:8589-8596.

Amir R, Michaelis M, Devor M (2002a) Burst discharge in primary sensory neurons: triggered by subthreshold oscillations, maintained by depolarizing afterpotentials. J Neurosci 22:1187-1198.

Amir R, Liu C-N, Kocsis JD, Devor M (2002b) Oscillatory mechanism in primary sensory neurones. Brain 125:421-435.

Araujo MC, Sinnott CJ, Strichartz GR (2003) Multiple phases of relief from experimental mechanical allodynia by systemic lidocaine: responses to early and late infusions. Pain 103:21-29.

Bostock H, Sears TA, Sherratt RM (1981) The effects of 4-aminopyridine and tetraethylammonium ions on normal and demyelinated mammalian nerve fibres. J Physiol (Lond) 313:301-315.

Bowe CM, Kocsis JD, Waxman SG (1985) Differences between mammalian ventral and dorsal spinal roots in response to blockade of potassium channels during maturation. Proc R Soc Lond B Biol Sci 224:355-366.

Cabanes C, Viana F, Belmonte C (2003) Differential thermosensitivity of sensory neurons in the guinea pig trigeminal ganglion. J Neurophysiol 90:2219-2231.

Calvin WH, Howe JF, Loeser JD (1977) Ectopic repetitive firing in focally demyelinated axons and some implications for trigeminal neuralgia. In: Pain in the trigeminal region (Anderson D, Matthews B, eds), pp 125-136. Amsterdam: Elsevier/North-Holland.

Castle NA, Haylett DG, Jenkinson DH (1989) Toxins in the characterization of potassium channels. Trends Neurosci 12:59-65.

Catterall WA (1987) Common modes of drug action on $\mathrm{Na}^{+}$channels: local anaesthetics, antiarrhythmics and anticonvulsants. Trends Pharmacol Sci 8:57-65.

Chabal C, Jacobson L, Burchiel K (1989) Pain responses to perineuronal injection of normal saline, gallamine, and lidocaine in humans. Pain 36:321-325

Chaplan SR, Bach FW, Shafer SL, Yaksh TL (1995) Prolonged alleviation of tactile allodynia by intravenous lidocaine in neuropathic rats. Anesthesiology 83:775-785.

Devor M (1983) Potassium channels moderate ectopic excitability of nerveend neuromas in rats. Neurosci Lett 40:181-186.

Devor M (1989) The pathophysiology of damaged peripheral nerve. In: Textbook of pain, Ed 2 (Wall PD, Melzack R, eds), pp 63-81. London: Churchill-Livingstone.

Devor M, Seltzer Z (1999) Pathophysiology of damaged nerves in relation to chronic pain. In: Textbook of pain, Ed 4 (Wall PD, Melzack R, eds), pp 129-164. London: Churchill Livingstone.

Devor M, Wall PD (1990) Cross excitation among dorsal root ganglion neurons in nerve injured and intact rats. J Neurophysiol 64:1733-1746.

Devor M, Govrin-Lippmann R, Frank I, Raber P (1985) Proliferation of primary sensory neurons in adult rat dorsal root ganglion and the kinetics of retrograde cell loss after sciatic nerve section. Somatosensory Res 3:139-167.

Devor M, Wall PD, Catalan N (1992) Systemic lidocaine silences ectopic neuroma and DRG discharge without blocking nerve conduction. Pain 48:261-268.

Djouhri L, Lawson SN (2004) A $\beta$-fiber nociceptive primary afferent neurons: a review of incidence and properties in relation to other afferent A-fiber neurons in mammals. Brain Res Brain Res Rev 46:131-145.

Eng DL, Gordon TR, Kocsis JD, Waxman SG (1988) Development of 4-AP and TEA sensitivities in mammalian myelinated nerve fibers. J Neurophysiol 60:2168-2179.

Everill B, Kocsis JD (1999) Reduction in potassium currents in identified cutaneous afferent dorsal root ganglion neurons after axotomy. J Neurophysiol 82:700-708.

Everill B, Rizzo MA, Kocsis JD (1998) Morphologically identified cutaneous afferent DRG neurons express three different potassium currents in varying proportions. J Neurophysiol 79:1814-1824.

Everill B, Cummins TR, Waxman SG, Kocsis JD (2001) Sodium currents of large (A $\beta$-type) adult cutaneous afferent dorsal root ganglion neurons display rapid recovery from inactivation before and after axotomy. Neuroscience 106:161-169.

Fedulova SA, Vasilyev DA, Veselovsky NS (1998) Voltage-operated potassium currents in the somatic membrane of rat dorsal root ganglion neurons: ontogenetic aspects. Neuroscience 85:497-508.

Frankenhaeuser B, Huxley AF (1964) The action potential in the myelinated nerve fiber of Xenopus laevis as computed on the basis of voltage clamp data. J Physiol (Lond) 171:302-315.

Gold MS, Shuster MJ, Levine JD (1996) Characterization of six voltagegated $\mathrm{K}^{+}$currents in adult rat sensory neurons. J Neurophysiol 75:2629-2646.

Gottrup H, Kristensen AD, Bach FW, Jensen TS (2003) Aftersensations in experimental and clinical hypersensitivity. Pain 103:57-64.

$\mathrm{Ha} \mathrm{H} \mathrm{(1970)} \mathrm{Axonal} \mathrm{bifurcation} \mathrm{in} \mathrm{the} \mathrm{dorsal} \mathrm{root} \mathrm{ganglion} \mathrm{of} \mathrm{the} \mathrm{cat:} \mathrm{a} \mathrm{light}$ and electron microscopic study. J Comp Neurol 140:227-240.

Hille B (2001) Ionic channels of excitable membranes, Chap 5, Ed 3. Sunderland, MA: Sinauer.

Hines ML, Carnevale NT (1997) The NEURON simulation environment. Neural Comput 9:1179-1209.

Honmou O, Utzschneider DA, Rizzo MA, Bowe CM, Waxman SG, Kocsis JD (1994) Delayed depolarization and slow sodium currents in cutaneous afferents. J Neurophysiol 71:1627-1637.

Ishikawa K, Tanaka M, Black J, Waxman S (1999) Changes in expression of voltage-gated potassium channels in dorsal root ganglion neurons following axotomy. Muscle Nerve 22:502-507.

Ito M (1959) An analysis of potentials recorded intracellularly from the spinal ganglion cell. Jpn J Physiol 9:20-32.

Ito M, Takahashi I (1960) Impulse conduction through spinal ganglion. In: Electrical activity of single cells (Katsuki Y, ed), pp 159-179. Tokyo: Igakushoin.

Kapoor R, Li Y-G, Smith K (1997) Slow sodium-dependent potential oscillations contribute to ectopic firing in mammalian demyelinated axons. Brain 120:647-652.

Kocsis JD, Devor M (2000) Altered excitability of large diameter cutaneous afferents following nerve injury: consequences for chronic pain. In: Proceedings of the Ninth World Congress on Pain. Progress in pain research and management (Devor M, Rowbotham MC, Wiesenfeld-Hallin Z, eds), pp 119-135. Seattle: International Association for the Study of Pain.

Kocsis JD, Waxman SG, Hildebrand C, Ruiz JA (1982) Regenerating mam- 
malian nerve fibers: changes in action potential wave form and firing characteristics following blockage of potassium conductance. Proc R Soc Lond B Biol Sci 217:77-87.

Kocsis JD, Bowe CM, Waxman SG (1986) Different effects of 4-aminopyridine on sensory and motor fibers: pathogenesis of paresthesias. Neurology $36: 117-120$.

Koerber HR, Mendell LM (1992) Functional heterogeneity of dorsal root ganglion cells. In: Sensory neurons (Scott SA, ed), pp 77-96. New York: Oxford UP.

Lai J, Porreca F, Hunter JC, Gold MS (2004) Voltage-gated sodium channels and hyperalgesia. Annu Rev Pharmacol Toxicol 97:371-397.

Lees G (1996) The effects of anticonvulsants on 4-aminopyridine-induced bursting: in vitro studies on rat peripheral nerve and dorsal roots. $\mathrm{Br} \mathrm{J}$ Pharmacol 117:573-579.

Lisney SJW, Devor M (1987) Afterdischarge and interactions among fibers in damaged peripheral nerve in the rat. Brain Res 415:122-136.

Liu C-N, Michaelis M, Amir R, Devor M (2000) Spinal nerve injury enhances subthreshold membrane potential oscillations in DRG neurons: relation to neuropathic pain. J Neurophysiol 84:205-215.

Liu C-N, Devor M, Waxman SG, Kocsis JD (2002) Subthreshold oscillations induced by spinal nerve injury in dissociated muscle and cutaneous afferents of mouse DRG. J Neurophysiol 87:2009-2017.

Lutzky I, Aiser F, Mor N (1984) The "Sabra" rat: definition of a laboratory animal. Isr J Med Sci 20:603-612.

Matzner O, Devor M (1992) $\mathrm{Na}^{+}$conductance and the threshold for repetitive neuronal firing. Brain Res 597:92-98.

Matzner O, Devor M (1993) Method for distinguishing between drug action on impulse propagation versus impulse generation. J Neurosci Methods 49:23-31.

Michaelis M, Blenk K-H, Janig W, Vogel C (1995) Development of spontaneous activity and mechano-sensitivity in axotomized afferent nerve fibers during the first hours after nerve transection in rats. J Neurophysiol 74:1020-1027.

Pedroarena CM, Pose IE, Yamuy M, Chase MH, Morales FR (1999) Oscillatory membrane potential activity in the soma of a primary afferent neuron. J Neurophysiol 82:1465-1476.
Puil E, Gimbarzevsky B, Spigelman I (1988) Primary involvement of $\mathrm{K}^{+}$ conductance in membrane resonance of trigeminal root ganglion neurons. J Neurophysiol 59:77-89.

Puil E, Miura R, Spigelman I (1989) Consequences of 4-aminopyridine applications to trigeminal root ganglion neurons. J Neurophysiol 62:810-820.

Safronov BV, Bischoff U, Vogel W (1996) Single voltage-gated K ${ }^{+}$channels and their functions in small dorsal root ganglion neurones of rat. J Physiol (Lond) 493:393-408.

Sheen K, Chung JM (1993) Signs of neuropathic pain depend on signals from injured nerve fibers in a rat model. Brain Res 610:62-68.

Spencer P, Raine CS, Wisniewski H (1973) Axon diameter and myelin thickness-unusual relationship in dorsal root ganglia. Anat Rec 176:225-244.

Strong PN (1990) Potassium channel toxins. Pharmacol Ther 137-162.

Sukhotinsky I, Ben-Dor E, Raber P, Devor M (2004) Key role of the dorsal root ganglion in neuropathic tactile hypersensibility. Eur J Pain 8:135-143.

Tagini G, Camino E (1973) T-shaped cells of dorsal ganglia can influence the pattern of afferent discharge. Pflügers Arch 344:339-347.

Targ EF, Kocsis JD (1986) Action potential characteristics of demyelinated rat sciatic nerve following application of 4 -aminopyridine. Brain Res 363:1-9.

Torebjork H, Lundberg L, LaMotte R (1992) Central changes in processing of mechanoreceptive input in capsaicin-induced secondary hyperalgesia in humans. J Physiol (Lond) 448:765-780.

Wu N, Hsiao C-F, Chandler S (2001) Membrane resonance and subthreshold membrane oscillations in mesencephalic $\mathrm{V}$ neurons: participants in burst generation. J Neurosci 21:3729-3739.

Xing J-L, Hu S-J, Long K-P (2001) Subthreshold membrane potential oscillations of type A neurons in injured DRG. Brain Res 901:128-136.

Xing J-L, Hu S-J, Jian Z, Duan J-H (2003) Subthreshold membrane potential oscillation mediates the excitatory effect of norepinephrine in chronically compressed dorsal root ganglion neurons in the rat. Pain 105:177-183. 